\title{
SiTUACIÓN SOCIAL, ORGANIZACIÓN Y LUCHAS CAMPESINAS EN MÉXICO, 1928-1935
}

José Rivera Castro*

\section{Resumen}

Este artículo trata sobre el papel del campesinado durante el periodo denominado de transición política del México posrevolucionario. Los trabajadores del campo realizaron grandes esfuerzos para modificar las estructuras rurales y lograr justicia social. El peso de la organización agraria se mostró fundamentalmente a través de la organización y las luchas regionales.

Palabras clave: campesinado, organización agraria, caudillismo, reforma agraria, latifundio, movilización campesina.

\section{Abstract}

This work focuses on the peasant actions that took place in Mexico after the Revolution, during the so-called political transition period. The country workers made serious attempts in order to modify the rural structures and obtain social justice. The impact of the agrarian organization was more manifest in regional spaces.

Key words: peasants, agrarian organization, leadership, agrarian reform, large landed state, peasant unrest.

* Universidad Autónoma Metropolitana. 
México ha sido, a lo largo de la historia contemporánea, un escenario de movimientos sociales. En el medio rural surgieron numerosos conflictos, relevantes para la conformación del Estado; el asesinato de Álvaro Obregón, presidente electo, se dio en un momento muy cercano a la crisis internacional de 1929, acontecimiento que impactó la economía nacional. El deceso del caudillo sonorense ocurrió en una sociedad que mostraba cambios, problemas y enfrentamientos violentos en el seno de los grupos de poder que obstaculizaban aun más la resolución de los problemas del campesinado. Movimientos políticos se manifestaban, como la rebelión militar "escobarista" (marzo de 1929), el final de la rebelión cristera, el "vasconcelismo", el inicio y fundación del Partido Nacional Revolucionario (PNR), el debilitamiento del Partido Nacional Agrarista (PNA) y de la Confederación Regional Obrera Mexicana (CROM), la escisión de la Liga Nacional Campesina (LNC) y la persecución del Partido Comunista (PC), entre otros hechos.

En los años veinte, sectores importantes del campesinado avanzaron en su organización y otras actividades que proponían transformar las estructuras del latifundismo y poner en marcha cambios que mejorarían las condiciones sociales. Este artículo es parte de un trabajo más amplio: estudiar la política agraria y los movimientos campesinos de México durante 1920-1940. Para este trabajo se ha considerado tratar la problemática campesina a través de una concepción regional, es decir, abordando los casos en diversos estados y territorios de la república. La idea central del artículo es acercarse a un panorama general de la movilización campesina. La información existente sobre el campesinado del país, es muy amplia; fundamentalmente la base de datos para este trabajo procede de los fondos del Archivo General de la Nación (AGN); de documentos provenientes de la hemeroteca y salas de la Biblioteca Nacional y de diversas instituciones de los estados de la república.

\section{La situación social}

A finales de los años veinte, Chihuahua seguía siendo uno de los bastiones más relevantes del latifundismo. La mayoría de las familias y empresas propietarias de las principales haciendas durante el Porfiriato continuaban 
manteniendo hegemonía económica en el campo. Las compañías agrícolas como la Palomas Land and Cattle Co. (ochocientas noventa y cinco mil hectáreas), la hacienda de San José Babícora del empresario Hearst (trescientas cincuenta mil hectáreas), la Cargil Lumber (doscientos diecinueve mil hectáreas) y por lo menos otra media docena de grandes propiedades estaban en manos de propietarios con intereses procedentes del viejo régimen.

El proceso revolucionario chihuahuense había logrado una enorme movilización social, los habitantes de los pueblos cerraron filas masivamente junto con los rebeldes Pascual Orozco y Francisco Villa y así realizaron la revolución más larga y popular del país. Los presidentes en turno, Álvaro Obregón y Plutarco Elías Calles, intentaron -tibiamente- emprender la transformación de la entidad; seguramente pensaron que si aplicaban una política de reforma agraria que afectara a los grandes latifundios se originarían problemas diplomáticos con Estados Unidos y otros países. En cuanto a los gobernantes locales, éstos tampoco hicieron esfuerzos para realizar importantes cambios agrarios.

Al comenzar los años treinta, Chihuahua mostraba un escenario desolador donde la penuria, el hambre y desempleo estaban presentes. Por parte del gobierno del país no existía un proyecto ni compromiso para transformar la entidad y mejorar la situación campesina. Creció la emigración de habitantes pobres y marginados hacia otras zonas de la república y a países como Estados Unidos. Había inseguridad, asaltos y bandolerismo, también existía escasez de transporte y medios de comunicación necesarios para los habitantes. Los campesinos vivían un estado de violencia, hecho que era denunciado ante la opinión pública y ante los presidentes de la nación; los líderes locales mencionaban, entre otros hechos, la masacre de Zamaloapan (once agraristas); el líder campesino André Mendoza, señalaba que los ejidos y las cabeceras de los distritos estaban protegidos por fuerzas federales que pretendían ejercer presión sobre los trabajadores del campo con el fin de mantener los intereses del gobierno local. ${ }^{1}$

1 Carta de Andrés Mendoza, presidente de la Liga de Comunidades Agrarias de Chihuahua a Abelardo L. Rodríguez, presidente de la República, 25 de julio de 1934, p. 3. Archivo General de la Nación (en adelante AGN), Presidentes, Abelardo L. Rodríguez, exp. 505.5/75-1. 
Durango fue una de las entidades que más sufrió el proceso revolucionario, la violencia armada se extendió durante diez años. La primera parte del periodo de la reconstrucción económica y política del país inició un proceso de estabilización de los territorios problemáticos. Después de la muerte de Obregón, amplios sectores duranguenses continuaban padeciendo los males producidos por el sistema latifundista. La pobreza y la injusticia social caracterizaban amplios sectores, pues los cambios y el mejoramiento eran impedidos por las familias terratenientes, quienes junto con altos cargos militares y caciques impedían la transformación que beneficiara al campesinado. Las enfermedades, la falta de educación y de vivienda, el desempleo, la inseguridad, la violencia, y muchos males más, aquejaban a Durango. Todavía existían numerosos casos de peones acasillados y de tiendas de raya en las haciendas.

En 1928, la Secretaría de Agricultura elaboró un informe sobre la situación laboral en la región lagunera. Ésta se ubicaba en el territorio algodonero más rico del país y comprendía cinco municipios de Coahuila y cuatro de Durango. En dicho documento se asentaba que, luego de entrevistar a muchos propietarios y administradores de haciendas de la zona, señalaron su bondad y paternalismo frente a las condiciones en que vivían decenas de miles de trabajadores. ${ }^{2}$ Varias décadas antes era bien conocida la inexistencia de los derechos laborales. Un numeroso grupo de trabajadores estaba compuesto por peones acasillados, sujetos (como en otros lugares) a la tienda de raya; otros llegaban del centro de México acompañados de sus familias. En diversos sitios, dueños y administradores adquirieron fama por el mal trato que daban a su personal laborante. Realmente, muy pocos propietarios construyeron instalaciones para escuelas y se carecía de una política médicoasistencial que diese servicio a sus peones. Algunos hacendados construían casas de adobe para los trabajadores de confianza o aceptaban que algunos edificaran chozas en terreno de las fincas. En los casos en que los peones ocupaban espacios de la hacienda y solicitaban la aplicación de las leyes para su protección, los patrones procedían a expulsarlos y les destruían sus casas, de tal forma que, por ejemplo, no pudieran probar la residencia legal marcada por la ley como un requisito para exigir el derecho al reparto de tierras. ${ }^{3}$

$2 \mathrm{sAF}$, Informe general de la Comisión de Estudios de la Comarca Lagunera, p. 289.

3 Restrepo, Iván, La agricultura colectiva en México, p. 22. 
Si bien es cierto que había grupos de trabajadores que laboraban constantemente en las fincas y vivían en casitas y chozas de adobe, no era el caso de la mayoría campesina, la que por circunstancias especiales no tenía trabajo definitivo en la hacienda, con excepción de unos cuantos. En cambio, miles de peones andaban errantes de hacienda en hacienda en busca de trabajo, estableciéndose por temporadas en cualquiera de ellas.

Hubo núcleos de la población que anteriormente se habían instalado en las fincas pero, aunque vivían dentro del terreno no laboraban de manera permanente en ellas. Crecieron diversos asentamientos y se llegaron a formar núcleos de cientos de habitantes, fue el caso de la estación Sacramento, el de Santa Teresa y varios otros en el perímetro de Arcinas. Estos lugares, al cumplir poco a poco los requisitos marcados por la ley agraria para obtener tierras, provocaron que los hacendados los destruyeran. ${ }^{4}$

Los trabajadores del campo lagunero vivieron condiciones muy injustas: los salarios eran deficientes y con jornadas agotadoras; los peones "lugareños" vivían hacinados en "cuadras" de la finca y los temporales en moradas improvisadas; padecían una alimentación precaria y sufrían más de una docena de enfermedades que los debilitaba y aniquilaba, mientras que el analfabetismo rebasaba el $80 \%$ de los habitantes. ${ }^{5}$

Este panorama social originó numerosos conflictos por la propiedad entre los dueños y los distintos sectores de trabajadores en toda la región lagunera, situación que preparó el terreno para la organización sindical que logró la desaparición del viejo sistema de haciendas sustituyéndolo por el ejido colectivo.

Tamaulipas era uno de los estados donde -a pesar de tener pocos habitantes y poseer grandes recursos agrícolas-, la población campesina padecía por carecer de las necesarias condiciones sociales básicas. Los hacendados se comportaban todavía como grandes señores que no cumplían los señalamientos constitucionales con la parte laboral de sus empresas. El estado, con una superficie de alrededor de ochenta mil kilómetros, contaba con extensos bosques de maderas finas, amplios espacios ganaderos, características favorables para la agricultura en la mayor parte de su

4 Liga de Agrónomos Socialistas, El colectivismo agrario en México. La Comarca Lagunera, p. 130. 5 Ibid., p. 131. 
suelo, con territorios fértiles en las llanuras del centro y del norte. Destacaba la producción algodonera en Matamoros, Reynosa y Río Bravo, también se producía algodón en el centro de la entidad, asimismo, sobresalía el cultivo de la caña de azúcar en Gómez Farías y otros lugares como El Mante que adquirió fama de gran emporio azucarero y en él la familia del general Plutarco E. Calles y varios políticos y militares -como el abogado Aarón Sáenz y el general Gregorio Osuna- invirtieron importantes capitales.

La entidad fue un territorio de enormes privilegios tanto para compañías e inversionistas extranjeros como para políticos relevantes del régimen. El sistema agrario mostraba el peso del latifundismo; un total de 18 hacendados detentaban 2,198,490 hectáreas. Los diez principales terratenientes acaparaban 1,800,396 hectáreas.

En Veracruz la estructura de la propiedad agraria era prácticamente la misma que al final del gobierno porfirista. La oligarquía local seguía siendo poderosa y pretendía acomodarse a pesar de los nuevos cambios políticos, representados por los intentos de algunos sectores de liquidar el antiguo esquema rural y poner en marcha un mejoramiento campesino.

Al finalizar la tercera década del siglo, Veracruz constituía una de las entidades económicas decisivas del país. Sus ricos recursos naturales posibilitaban llevar adelante amplias propuestas que beneficiaran a las clases trabajadoras: destacó la riqueza de la explotación petrolera, creció y aumentó el precio de las tierras, el estado poseía bosques que ocupaban $16 \%$ del suelo y una abundancia de diferentes tipos de maderas, a su vez, era importante la cría y venta de ganado.

La agricultura destacaba como una de las principales ramas económicas, las condiciones del terreno y el clima hacían de la entidad un sitio extraordinariamente fértil. Las principales microrregiones como la huasteca, el centro, el papaloapan, los tuxtlas y el istmo veracruzano poseían excelentes posibilidades agrícolas, con cultivos sobresalientes de maíz, arroz, chile y frijol, al igual que productos comerciales como el café, la caña de azúcar, el tabaco, la vainilla, el algodón, el hule y el cacao. Se obtenían también enormes cosechas de plátano, piña y otras frutas. ${ }^{6}$

6 SAF, Regiones económico-agricolas de la República Mexicana, pp. 386-401. 
La oligarquía y las empresas agrícolas que dominaban importantes extensiones de tierras carecían de un proyecto modernizador que contemplara una explotación racional del campo, un uso adecuado de la maquinaria y tecnología, así como una óptica empresarial que promoviera el mejoramiento de sus trabajadores. A ello se agregaba la llegada reciente de las inversiones petroleras, que provocó la destrucción de valiosas zonas agrícolas y el despojo de tierras a diversas comunidades indígenas.

Numerosas concesiones fueron otorgadas a capitalistas y empresas foráneas que explotaron terrenos de bosques, regiones cafetaleras, tabaqueras, azucareras, plataneras y productoras de otros bienes; el istmo veracruzano, la zona norte costeña y las ribereñas del Papaloapan eran un ejemplo de ese proceso. Como en otros estados, personajes políticos del régimen se convertían en nuevos latifundistas.

Este panorama -de privilegio para los hacendados-, revelaba la difícil situación laboral en los territorios del café, del tabaco, de la explotación maderera, del azúcar, de la producción bananera y de otros bienes agrícolas; había condiciones de desigualdad económica, enfermedades permanentes, insalubridad y una vivienda miserable. A ello se agregaba un escenario de caciquismo y de poderes locales represivos.

La problemática campesina oaxaqueña revelaba el poco interés por parte del gobierno federal por la población más pobre. En la entidad se habían efectuado muy pocos cambios para enfrentar las grandes desigualdades sociales; los diversos gobiernos posrevolucionarios no realizaron esfuerzos por emprender medidas que disminuyeran los problemas ocasionados por la miseria y la marginación. Los gobiernos locales de García Vigil, de los generales Ibarra y Onofre Jiménez, así como los de López Cortés y García Toledo rechazaban poner en marcha una política de reforma agraria.

En un Informe del Departamento Agrario, fechado en 1934, el general Heriberto Jara, representante presidencial en dicha entidad, señaló que en Oaxaca, desde 1915 hasta la fecha, se recibieron 710 expedientes, de los cuales sólo se respondió 125 , es decir, más de $80 \%$ de las solicitudes no fueron satisfechas. ${ }^{7}$

7 "Memorándum al C. General Heriberto Jara", AGN, Presidentes, Lázaro Cárdenas, exp. 404/4/8, p. 30 . 
Jorge L. Tamayo, destacado geógrafo ehistoriador, funcionario que ocupó varios cargos públicos, así como conocedor profundo de la problemática campesina, escribía que "la acción agraria fue insignificante; las pocas resoluciones se referían a superficies de pequeña monta y obedeciendo a veces a compromisos políticos o venganzas personales contra ciertos propietarios, pero no correspondían a una convicción revolucionaria. Los latifundios de Tuxtepec (Almazán, compañías fruteras y otras) y a los de la Costa, permanecieron intactos; el grave problema de las tierras comunales, siguió sin abordarlo".

El ingeniero Tamayo resaltaba en su obra que las autoridades oaxaqueñas permitieron que varios generales revolucionarios se posesionaran de enormes extensiones de tierras. El caso del futuro candidato a la presidencia del país, Juan Andrew Almazán, que se hizo dueño de cerca de cuarenta mil hectáreas en Tuxtepec es un ejemplo. ${ }^{9}$ Finalmente, continuaban viejos y nuevos problemas como el caciquismo regional, enemigo de un mejoramiento social; la emigración de trabajadores pobres a zonas productoras de tabaco, plátano, caña de azúcar, etc.; la tardanza -el llamado "tortuguismo" gubernamental- en la ejecución de las leyes agrarias; la protección de antiguos hacendados (la Cañada, el Istmo, la Costa, Papaloapan, etc.) y la emergencia de políticos convertidos en recientes dueños de latifundios; la marginación de la población indígena; la falta de protección a los jornaleros en las empresas de enclave y la inexistencia de justicia en el campo.

Después de la desaparición del dirigente Felipe Carrillo Puerto, muchos candidatos a ocupar puestos públicos, así como diversos gobernantes de Yucatán y del país, se comprometieron a terminar con la terrible situación en que vivían los peones de las haciendas. Los años pasaban y continuaba la concentración de la propiedad en manos de unos cuantos dueños en las principales zonas de la península; muchos de los avances y aspiraciones de las grandes masas quedaban frustrados. Los ex presidentes Álvaro Obregón y Plutarco Elías Calles dejaron incumplidas las promesas a los campesinos. La "casta de negreros" -como le llamó el general sinaloense Salvador Alvarado- continuaba dominando el negocio agrícola industrial

8 Tamayo, Jorge L., Oaxaca en el siglo XX, p. 68.

9 Idem. 
del henequén; durante varios años se había burlado la legislación agraria archivando solicitudes y resoluciones presidenciales. Hernán Laborde, estudioso y conocedor de la cuestión agraria, escribía que el panorama yucateco presentaba "una vasta red de intrigas, sobornos, chanchullos, argucias legales, amenazas y crímenes, tejida con hilos de henequén y a menudo ensangrentada". ${ }^{10}$

En su investigación sobre las condiciones vitales y laborales de los peones, Siegfried Azkinasy señalaba la destrucción física de la población, indicaba que a la dieta de los habitantes en la zona henequenera le faltaba entre $55 \%$ y $70 \%$ de las calorías esenciales para la subsistencia. Con salarios de 84 centavos diarios, la desnutrición y las enfermedades propias del hambre destruían inevitablemente a los mayas; en la hacienda de Sacapu morían 318.2 de cada mil niños menores de un año; las enfermedades gastrointestinales, las causadas por deficiencias vitamínicas, la tuberculosis y el paludismo eran causales de que la mortalidad rural fuera muy superior al promedio nacional. ${ }^{11}$

Haciendo un recuento de la política agraria al iniciar los años treinta, cabe destacar que prácticamente no hubo dotaciones de tierras; ni siquiera se mencionaba la existencia de medidas sociales que beneficiaran al campesinado; la desocupación rural afectaba a decenas de miles de trabajadores. En resumen, se mantuvieron intocables las fincas henequeneras; el gobierno aplicó la ley sin la decisión que exigían los cambios necesarios en las estructuras agrarias. La política de reparto de tierras debía depender del interés de los gobernadores, los cuales estaban obligados a responder a las solicitudes campesinas. Ante los obstáculos -y vacilaciones- de los gobernantes para resolver la problemática de los peones, se generaba un descontento con fuertes expresiones de resistencia y oposición campesina expresado en marchas indígenas a la ciudad de Mérida, huelgas de jornaleros en varias fincas y ocupación de otras. ${ }^{12}$

10 Laborde, Hernán, "Cárdenas, reformador agrario", p. 74.

11 Azkinazy, Siegfred. El problema agrario de Yucatán, p. 65.

12 Carta del ingeniero Candelario Reyes al presidente Lázaro Cárdenas. AgN, Presidentes, Lázaro Cárdenas, exp. 404.1-12. 
En torno al estudio de la organización y de los movimientos agrarios en Chiapas, este estado se caracterizó por la diversidad de su población distribuida en microrregiones, con distintas raíces y tradiciones históricas y culturales. Hay que destacar también las variadas economías locales como la de plantaciones, producción maderera, la ganadería, entre otras.

Difícilmente podríamos encontrar una entidad del país donde más se careciera de una política gubernamental interesada en mejorar la situación laboral de los peones. Como lo afirma Antonio García de León, los terratenientes se acomodaron en una particular alianza con el poder político que les permitió sobrevivir a la reforma agraria nacional. ${ }^{13} \mathrm{El}$ mismo autor menciona que una añeja tradición soberanista y una particular conformación de su territorio hicieron posible desviar las demandas campesinas hacia la colonización del trópico húmedo y mantener incólume el latifundio, la pequeña propiedad atrasada y, sobre todo, las relaciones de producción todavía basadas en el peonaje de corte porfiriano. ${ }^{14}$ Varios estudiosos de la condición en Chiapas han abordado la situación de la inmensa mayoría de los trabajadores; los hermanos Weyl, historiadores estadounidenses escribieron en su recorrido que los indígenas de las fincas habían "sido arrancados de su cultura de maíz primitiva, por las exigencias de la agricultura sujeta al sistema de plantación". ${ }^{15}$ Asimismo, los autores agregaban que, como forma de contratación, todos los años los propietarios distribuían bebidas entre los trabajadores, luego los transportaban en autobuses a las haciendas y los hacían firmar documentos que los comprometían por doce meses. ${ }^{16}$ Ciertamente, las prácticas de contratación laboral atentaban contra la legislación mexicana. A todo ello hay que agregar que el campesinado chiapaneco era uno de los más explotados. En la zona cafetalera del Soconusco y en otras regiones agrícolas y ganaderas se combinaban la servidumbre por deuda, las enfermedades, la desnutrición, la mortalidad infantil, la injusticia, etc. ${ }^{17}$ Una amplia documentación y bibliografía testimonia las condiciones laborales en ese territorio sureño.

13 García de León, Antonio, Presentación, El reparto de tierras y la politica agraria en Chiapas, 1914-1988, p. 10.

14 Idem.

15 Weyl, Nathaniel y Silvia Weyl, "La reconquista de México", pp. 230-231.

16 Ibid., p. 231.

17 Marion, Odile, El agrarismo en Chiapas, pp. 107-113. 
El peso de la oligarquía chiapaneca gozaba de tal poder que impedía la realización de la reforma agraria; los terratenientes poseían una gran autonomía frente al poder federal, preparaban movimientos armados para impedir las acciones que favorecieran a los peones. María Eugenia Reyes Romero -una de las estudiosas más serias de los movimientos agrarios del México posrevolucionario-, apunta en una de sus investigaciones que la población campesina se encontraba fuertemente cohesionada por el dominio de la finca y ligada por una estructura social muy compleja (clientelismo, parentesco, etc.) a los terratenientes. ${ }^{18}$

\section{Organización y luchas campesinas}

La organización y la lucha agraria en Chihuahua se manifestaban en condiciones difíciles para los distintos grupos de campesinos. Varios grupos de trabajadores (vaqueros, peones, temporeros, etc.) participaron en el proceso revolucionario que se inició en 1910; primero en las filas rebeldes maderistas, más tarde con la División del Norte dirigida por el general Francisco Villa. Después de la derrota militar de Villa en Celaya y después de su retirada de Agua Prieta, Sonora, el general duranguense organizó la guerrilla que duró de 1916 a 1920 con el apoyo de numerosos habitantes de los pueblos. Entre los guerrilleros destacaban campesinos y vaqueros que se habían enfrentado a las defensas sociales gubernamentales y que, más tarde, participaron en diversas acciones contra el poderoso latifundismo y otros grupos de poder local. Estos últimos se situaban prácticamente al lado de los intereses de los hacendados.

La información procedente del Archivo General de la Nación (AGN) y de diversos acervos regionales nos muestra el poder de las empresas agrícolas de propietarios estadounidenses, así como de la oligarquía local, que todavía conservaba extensas propiedades, pues el contubernio con gobernadores protegía los intereses latifundistas. Hay que agregar el hecho de que muchos revolucionarios, convertidos en políticos, adquirían -de distintas manerasextensos terrenos de haciendas.

18 Ibid., pp. 123-124. 
En diversos congresos y asambleas agrarias habían participado delegados que mostraron su irritación por la carencia de una política estatal que favoreciera al grueso de los trabajadores. Entre las cuestiones relevantes que se trataban, menciono algunas de ellas: la modificación al contrato de aparcería agrícola establecida por la caja de préstamos en el latifundio de la familia Terrazas; la tardanza en la realización de trámites de demandas campesinas; propuestas de créditos; el fraccionamiento de grandes haciendas para distribuir entre el campesinado.

Las ligas agrarias realizaban encuentros colectivos para discutir las formas de asociación, los mecanismos de defensa frente al latifundismo, las relaciones políticas, la vinculación del campesino chihuahuense con las agrupaciones del país, etcétera.

Los últimos años veinte y los primeros de la siguiente década vieron la formación de diversas asociaciones agrarias en la entidad. Se habían creado, entre otras: la Unión de Obreros y Campesinos del Distrito Hidalgo, la Agrupación Agrarista Ignacio Zaragoza, Agricultores y Campesinos de La Gomera, la Liga Regional Campesina Valle de Olivos, la Liga de Comunidades Agrarias del estado de Chihuahua, entre otras.

Después del acuerdo de pacificación villista con el gobierno federal -decisión que afectaba ampliamente a la región lagunera-, la movilización campesina había cobrado fuerza, lo cual se manifestó en las reuniones donde activistas plantearon ideas para transformar el campo e iniciar un mejoramiento social. Se preparaban congresos y se constituían asociaciones defensoras de los trabajadores. En La Laguna continuaban las antiguas estructuras de poder, fenómeno que mostraba los obstáculos de la organización agraria. Los hacendados contaban con el apoyo de jueces, gobiernos locales, del ejército (jefes militares de zona), la iglesia, así como de otros actores de poder regional.

La crisis de 1929 afectaba a La Laguna: las fincas algodoneras y de otros productos habían quedado impactadas por consecuencias como la disminución de los precios de exportación de diversas materias agrícolas; la crisis se iba agudizando cada día. El corresponsal de Excélsior en San Pedro de las Colonias escribía: "Todos los labriegos quejosos han sido despedidos por sus patrones por haberse sindicalizado en las Uniones de Campesinos, cuyas tendencias juzgan comunistas los hacendados, aunque las Uniones 
figuren como de agraristas. En muchas haciendas y ranchos últimamente se constituyeron esas Uniones, organizadas por algunos líderes que hicieron propaganda al efecto, y desde su constitución datan las dificultades entre los unionistas y los terratenientes. Muchos de los labriegos adheridos a las Uniones, se han segregado de ellas para evitar dificultades con los patrones y sobre todo la desocupación, cosa que les impediría atender a la subsistencia de su familia. Como resultado de la acción represiva, ejercida por los hacendados contra los unionistas, con el fin de evitarse en lo futuro dificultades más graves, la Junta Municipal de Conciliación se ha visto agobiada con extraordinario número de unionistas despedidos por los hacendados". ${ }^{19}$

A finales de marzo de 1932, el periódico El Nacional publicaba: "Nunca en la historia de la Comarca Lagunera se había presentado una situación económica tan desastrosa como la presente; la aguda crisis reinante está adquiriendo tintes de tragedia, ya que millares y millares de labriegos famélicos, van de una hacienda a otra, en busca de ocupación, sin encontrarla..." ${ }^{20}$ El Universal, por su parte, informaba: “...en el municipio de San Pedro de las Colonias cerca de treinta mil campesinos carecen de ocupación". ${ }^{21}$ El Machete agregaba: "Las siembras de maíz y trigo en todo el país serán reducidas este año en un 25\% y las de algodón en un $70 \%$. La perspectiva es, por lo tanto, de agravación tremenda de la crisis agraria en todo el país y muy especialmente en La Laguna". ${ }^{22}$

En la región existía un gran malestar, la crisis en el campo había originado inseguridad, desempleo y descontento de importantes sectores de la población. Por otra parte, la organización sindical agraria continuaba en varios sitios. A pesar de que los sindicatos del país atravesaban grandes dificultades, las luchas sociales se incrementaban ampliamente en La Laguna. Se expresaba una fuerte participación sindical en agrupaciones campesinas y núcleos de activistas pertenecientes al Partido Comunista. Guadalupe Rodríguez, tesorero de la LNC, y uno de los principales líderes de la región, había sido asesinado al final de la década de los veinte. Junto con

19 Excélsior, 19 de junio de 1929.

20 El Nacional, 24 de marzo de 1932.

21 El Universal, 25 de marzo de 1932.

22 El Machete, 28 de julio de 1928. 
otros militantes realizaba un amplio trabajo constituyendo comités agrarios en Torreón, El Rodeo, Durango y otros sitios. En Matamoros, Coahuila, se había preparado una lucha por reivindicaciones salariales, distribución de tierras y liberación de presos políticos. En esta ciudad se efectuó una marcha en la que los manifestantes demandaban aumentos salariales, distribución de tierras, disminución de la jornada laboral, etc.; apenas iniciada, policías y rurales la reprimieron, cayendo una veintena de campesinos. ${ }^{23}$

A pesar de la política coercitiva contra el campesinado, se habían impulsado acciones que influían en la fuerte movilización laboral de los años veinte y buena parte de la siguiente década. Muy pronto emergieron manifestaciones de peones decididos a mejorar su situación. La firma de contratos colectivos entre patrones y campesinos constituía una de las demandas que más se expresaron en ese torbellino popular. El derecho a recibir parcelas representaba una iniciativa que había logrado extenderse rápidamente a importantes zonas agrícolas. La presión ejercida por el estallido de decenas de huelgas en 1935 adquiría tal magnitud que el sindicalismo del país había decidido apoyar a los laguneros. Este movimiento desembocaba en la expropiación de las haciendas laguneras y en la creación del conjunto ejidal más importante de la república.

Uno de los movimientos sociales históricos más relevantes de México fue el que realizaron los pueblos indígenas pertenecientes al Valle del Yaqui en el estado de Sonora. El conflicto surgió por el despojo de varios cientos de miles de hectáreas a las comunidades. La compañía Richardson era la empresa que había obtenido el aval gubernamental para apoderarse de una gran extensión de terrenos. Inmediatamente, los afectados respondieron a dicha decisión. El gobierno federal movilizó al ejército, y comenzó una violenta campaña persecutoria contra los yaquis.

Durante muchos años las comunidades organizaron una lucha para que se les reintegraran sus tierras; numerosos yaquis participaron en los diferentes contingentes revolucionarios, pero no lograron que sus demandas fueran escuchadas, incluso, se reiniciaba una política gubernamental persecutoria, los generales obregonistas efectuaban terribles masacres de personas de esta etnia. En 1926 había estallado un levantamiento que llevó al presidente

23 Santos Valdés, José, Matamoros. Ciudad Lagunera, p. 204. 
Calles a ordenar una de las represiones más duras de su gobierno. En 1928, los terrenos se trasladaron de la empresa Richardson a manos del gobierno federal y a otras instancias. En 1929 se realizó un acuerdo para establecer un periodo pacífico. $\mathrm{Al}$ año siguiente comenzó un acercamiento con los yaquis. Varios años después, representantes de los pueblos inconformes se habían comunicado con Cárdenas manifestándole sus demandas. En octubre de 1937 el gobierno respondía favorablemente a varias de sus peticiones. La decisión presidencial quedaba publicada en el Diario Oficial de la Federación y se reconocía a los yaquis la tierra laborable situada sobre la margen derecha del río Yaqui, así como el agua necesaria para su irrigación. Se fijaba la extensión de ciento treinta mil hectáreas de planicie susceptibles de riego y cerca de trescientas mil hectáreas, situadas en la sierra y terrenos de pastizales. Al lograr solamente una parte de sus tierras, los yaquis presionaron para que se les restituyera el total de ellas, es decir, lo que realmente les pertenecía. Los terrenos faltantes ya habían sido ocupados por otros grupos de campesinos e incluso legalmente reconocidos como propiedad social de varios núcleos ejidales y comunales. ${ }^{24}$

A lo largo de mucho tiempo, la industria azucarera se ha significado por ser una de las principales ramas agrícolas en el país. Diversas entidades se han destacado por su producción y exportación, entre otras Morelos, Puebla, Veracruz y Sinaloa. La ciudad de Los Mochis, situada en el norte sinaloense, se caracterizaba por su destacado papel en la producción de azúcar; ahí estaba establecida la United Sugar Company que era una de las empresas estadounidenses donde los trabajadores crearon sindicatos. Como sucedía en otros sitios de México, encontraron muchos obstáculos para avanzar en sus propósitos ya que los empresarios mostraron una cerrazón para respetar las leyes en materia de trabajo. También se había dado el hecho, de que durante varios años, los gobiernos locales obstruían la actividad de las principales agrupaciones agrarias. En Los Mochis y otros lugares se lograba constituir asociaciones obrero-campesinas con una estrategia para avanzar en la organización y en materia de reivindicaciones. Las luchas laborales de este enclave azucarero influían para su expropiación, decisión gubernamental que originaba la entidad denominada Sociedad de

24 Escárcega, Everardo, Historia de la cuestión agraria. El cardenismo, pp. 175-176. 
Interés Colectivo Agrícola Ejidal (SICAE), organismo que se enfrentaría a los monopolios azucareros. Esta agrupación tuvo una amplia relación con otras formaciones locales y se integraba a un extenso proceso de movilización social del país. ${ }^{25}$ Vale la pena agregar que, entre sus actividades, había apoyado también la formación y las luchas de otras asociaciones agrarias y obreras de Sinaloa y de la república.

Durante muchos años, grupos de campesinos tamaulipecos realizaron una gran movilización que repercutió en la sociedad y la economía de la entidad. La región algodonera del Norte vivía una actividad reivindicativa que fue esencial en el proceso expropiatorio de haciendas controladas por intereses estadounidenses.

Poco después de terminada la Revolución mexicana, el campesinado se empezaba a agrupar en diversos poblados constituyendo la Liga de Comunidades Agrarias de Tamaulipas (septiembre de 1926). Durante los años veinte y principios de la siguiente década, fue una asociación que desempeñaba un papel decisivo en la movilización de los trabajadores en la entidad y en la república. Estuvo estrechamente vinculada a la corriente "portesgilista” y al Partido Socialista Fronterizo; sus líderes fueron parte del grupo que constituía la LNC, en la que participaban ampliamente hasta los años 1929-1930.

La liga tamaulipeca realizó grandes esfuerzos para favorecer al campesinado en Tamaulipas, pero vivió una situación muy peligrosa, ya que la actividad de sus militantes representaba un riesgo al existir "guardias blancas" armadas que protegían a los hacendados y se convertían en cuerpos de choque. La represión abarcaba, por supuesto, todo tipo de acción campesina que afectara los intereses del poder latifundista. Muchos activistas cayeron bajo las balas de los pistoleros.

A pesar de las dificultades e inestabilidad que prevalecían en el escenario agrario tamaulipeco, se logró construir una alternativa de defensa y de mejoramiento social para el campesinado. En los municipios algodoneros fronterizos de Reynosa y Matamoros se desarrollaban también importantes acciones agrarias. En Reynosa, Matamoros y otros sitios, el algodón generaba grandes fortunas a empresarios estadounidenses. El trato racista

25 Gil, Mario, "La conquista del Valle del Fuerte", pp. 13-58. 
y prepotente de los hacendados había obligado a la liga tamaulipeca a realizar un trabajo de defensa permanente.

En la Huasteca también realizaba una labor organizando a los azucareros. Las familias de los políticos revolucionarios Gregorio Osuna, Aarón Sáenz y el ex presidente Calles, controlaban los ingenios en esta zona provocando la molestia del campesinado, el cual tuvo que emprender un largo y duro movimiento reivindicativo. La misma organización ayudaba a preparar los expedientes de los demandantes de tierras y promovía las invasiones de haciendas y otras formas de lucha. Los congresos anuales celebrados por la misma agrupación representan un importante caudal de información para los historiadores, por la enorme información contenida en las recopilaciones que elaboraron sus directivos sobre diversas convenciones agrarias.

Michoacán ha sido uno de los estados del Bajío más relevantes por su producción agrícola. En varias zonas se generaba un latifundismo poderoso que había mantenido un trato injusto para sus trabajadores. Muy pronto, se crearían asociaciones que se proponían lograr un ambiento de justicia para la población campesina. En la región purépecha de este estado se constituía la Liga de Comunidades Agrarias, que llegó a ser una de las asociaciones más relevantes del campo, que asimismo, había participado en la formación de la LNC y realizado una gran labor de organización y de defensa de los peones. Colaboraba con diversas comunidades indígenas, preparando las demandas de los pueblos. Adquirió muy pronto el apoyo de comunidades autóctonas como las de Tarejero, Pátzcuaro, Naranja y otras. Organizó varias invasiones de haciendas y, como ocurría en aquellos años, los sectores del poder local y el ejército respondían con fuerza impidiendo que los campesinos tomaran las haciendas. Fueron años difíciles; terribles para los activistas; había un ambiente enrarecido y tenso, a ello se agregaban las presiones de los caciques y otras instancias coludidas con los hacendados. Como muchos líderes de esa época, Primo Tapia, principal dirigente del agrarismo michoacano, murió a causa de la represión.

Esta misma asociación se proponía desarrollar un movimiento agrario con apoyos internos y externos a la entidad. Puso en marcha un plan que comprendía la organización de varios congresos, alianzas con otras asociaciones y la búsqueda de acuerdos para constituir un mayor peso del campesinado nacional. 
Hacia 1928 importantes sectores agrarios se aliaron a grupos y figuras políticas regionales. Con el apoyo del gobernador Lázaro Cárdenas se constituía la Confederación Revolucionaria Michoacana del Trabajo (CRMDT), asociación que se había propuesto organizar a los trabajadores y efectuar una transformación en el medio rural. Al terminar el gobierno de Cárdenas en Michoacán, fue sustituido por enemigos locales, este hecho afectó a la CRMDT con los cambios que llevaron a cabo. Comenzaba un periodo de división en la dirección sindical y de represión hacia la corriente "cardenista" y a un sector ligado al PCM. Surgían también amenazas y persecuciones a las comunidades y pueblos que abrían un periodo difícil para el campesinado. Nueva Italia y Lombardía, haciendas de Tierra Caliente, veían cómo los peones realizaban una de las luchas más valientes, que respondían sin duda a un radicalismo heredado del movimiento agrario del inicio de los años veinte. ${ }^{26}$

Los conflictos en Lombardía y Nueva Italia eran parte del proceso de luchas campesinas michoacanas. A partir de 1930, estos latifundios arroceros llegaron a ser escenarios de enconadas movilizaciones; uno de los momentos más difíciles inicia en mayo de 1932 y concluiría en enero de 1934. El estallido de una huelga abrió el camino a una situación problemática; la organización sindical local preparaba un paro laboral en época de cosechas, luego un emplazamiento huelguístico que era declarado ilegal, más tarde una manifestación que culminó con una represión militar a los huelguistas y la muerte de varios activistas. Gerardo Zamora, dirigente campesino michoacano, fue asesinado. En la entidad se había originado un fuerte cuestionamiento a las formas autoritarias. ${ }^{27}$ En este conflicto, la lucha de los peones resultó definitiva para que pocos años después, las haciendas fueran expropiadas, comenzando un periodo de restitución de tierras a los pueblos en el que ambos latifundios fueron puestos en manos de sus trabajadores. ${ }^{28}$

26 Laborde, Hernán, op. cit., p. 74.

27 Informe de la CRMDT. AGN, Presidentes, Abelardo L. Rodríguez, exp. 06-36.

28 AGn, Presidentes, Abelardo L. Rodríguez, exp. 524-706. 
Haciendo un recuento podríamos decir que la actividad campesina veracruzana al final de los años veinte representaba un papel decisivo en la vida social y política de la entidad. Se habían organizado pequeñas luchas y luego grandes movilizaciones obteniendo logros relevantes. Se creó la asociación agraria local que impulsó ambiciosos proyectos para beneficio de numerosos pueblos: distribución de tierras, créditos, maquinaria agrícola, formación de cooperativas, escuelas rurales, etcétera. ${ }^{29}$

Sus dirigentes pertenecían a la vanguardia campesina nacional, que apoyaba la organización laboral y las luchas agrarias de los pueblos hasta lograr un movimiento sociopolítico de tal significado que debía de ser tomado en cuenta por las clases gobernantes. En consecuencia, la agrupación campesina se había convertido en un factor fundamental en la estructura del poder político y de las transformaciones operadas en su seno. Como consecuencia, tenía un comportamiento significativo en el escenario de la representación municipal y parlamentaria. De sus filas fueron surgiendo propuestas para transformar el país y planteamientos radicales para cambiar la sociedad. Desde un principio, sus líderes eran influidos por los procesos revolucionarios e ideológicos de la época, efervescencia social que determinaba la militancia de líderes y trabajadores en las asociaciones políticas nacientes; tal fue el caso del activismo campesino en el PCM y en distintas corrientes socialistas y de otras tendencias. ${ }^{30}$

La decisión de armar a muchos de sus miembros representaba una de las estrategias de la Liga. En la entidad, los activistas campesinos vivían en medio de la violencia ya que el poder de los terratenientes había establecido un clima de crímenes y asesinatos. Como en otros estados de la república, en Veracruz repercutía la inestabilidad política del país; las diversas rebeliones militares representaban un fenómeno que generaba las alianzas de los caudillos con los campesinos, situación que originaba la creación de contingentes rurales armados. En varios de los procesos políticos locales veracruzanos los caudillos vieron la necesidad de afianzar su poder por medio de la búsqueda de una base social. Esta línea de acción

29 Domínguez, Olivia, Politica y movimientos sociales en el tejedismo. 30 Almanza, Manuel, Historia del agrarismo en el estado de Veracru\%: 
exigía la vinculación de asociaciones campesinas y otras mediante alianzas; negociaciones que para los grupos participantes en los acuerdos significaba apoyarse mutuamente y fortalecerse para conseguir su objetivo.

Úrsulo Galván -considerado el principal dirigente del campesinado veracruzano y del país-; llevó por la entidad, y por muchos lugares de la república la idea de la organización y emancipación de los trabajadores. Murió al final de la década de los veinte después de que, junto con Manuel Almanza participara en reuniones clandestinas en Huatusco y actuara también entre los trabajadores de la región huasteca que libraban una lucha contra las empresas petroleras; para Galván todo ello representaba una escuela en el camino de los movimientos libertarios. Más tarde, se afiliaba al PCM, agrupación donde llegó a destacar como una personalidad fundamental; formó, junto con Almanza, una mancuerna ideológica y de lucha agrarista. Durante una década fue uno de los principales organizadores del movimiento campesino.

Después de la desaparición de Galván se recrudecieron los problemas dentro de la liga veracruzana. Los diversos conflictos internos y la represión en el campo -que duró muchos años-, originaron un fuerte debilitamiento de la agrupación. No obstante las excelentes relaciones que sus dirigentes anudaron con Adalberto Tejeda -la personalidad de mayor influencia política en la entidad-, no se resolvieron los principales problemas de los trabajadores. Dispersos, los diversos grupos rurales veracruzanos lucharon durante el periodo del "maximato". Con todo, los años treinta representarían una época en la que los campesinos retomarían el camino de la resistencia, la lucha por la tierra y otras demandas sociales.

En el campo duranguense la movilización laboral estaba estrechamente relacionada con la resistencia y las acciones realizadas por numerosos núcleos de población. En esta entidad, como en otras del Norte, grupos de campesinos se reunían y se preparaban para un largo y difícil enfrentamiento contra grandes terratenientes, compañías madereras, ganaderas, algodoneras y otras que recibían el apoyo de los gobernantes locales y de políticos de la administración federal. Las asociaciones agrarias manifestaban su deseo de que el Estado revolucionario los defendiera.

A pesar de la miseria en el campo y la necesidad de un cambio de vida de la población, los repartos de tierras y otras medidas agrarias eran escasos. 
Se efectuaban algunas dotaciones en Tapona, Muleros, Cacaria, Valle de Poanas y Valle de Guatimapé. ${ }^{31}$ Ya los peones y jornaleros enfrentaban la represión del hacendado, quien a través de sus mayordomos, capataces y guardias blancas, trataba de impedir la organización laboral. Los jerarcas de la iglesia católica impulsaban también una oposición a la existencia de asociaciones agrarias; asimismo, el ejército lo impedía y en numerosos casos reprimió violentamente las acciones agraristas. ${ }^{32}$

En torno a las asociaciones que luchaban por la obtención de tierras, la Liga de Agrónomos Socialistas mencionaba que hubo casos en que los trabajadores solicitaron dotación o restitución, otros prefirieron el fraccionamiento del latifundio, o bien se ampararon en la Ley de Tierras Ociosas. ${ }^{33}$ Por otra parte, ni los gobiernos locales ni el federal habían respondido con justicia a las peticiones campesinas: "actuaban sin una orientación precisa sujetos a diversas tendencias, y aún contradictorias, como lo eran los intereses económicos y sociales de los sectores que actuaron en la Revolución. La circunstancia de que la clase conservadora, no obstante haber sido derrotada militarmente, seguía o era tan tímida e imprecisa que podía deformarse en sentidos contradictorios, dieron lugar a que, lejos de resolverse de manera favorable las solicitudes elevadas por los campesinos, desde el momento en que hacían su petición, una existencia más penosa, pues se desencadenó sobre ellos la persecución y la falta de trabajo. Se conservó, en cambio, incólume el latifundio, que se apoyaba para su defensa, de una manera hábil, en las mismas leyes que deberían destruirlo". 34

En Los Llanos, región donde estaban ubicadas las haciendas de Tapona, la Catalina y otras, los trabajadores exigían el reparto de tierras ociosas. Se había constituido la Federación de Obreros y Campesinos de la zona. Lo mismo sucedía en lugares como Canatlán, Vicente Guerrero, Cuencamé, entre otros. ${ }^{35}$

Desde la formación de las asociaciones agrarias, los activistas del PCM impulsaban la organización campesina y ayudaban a enfrentar los problemas

31 León, Arturo, El movimiento campesino en los Llanos de Victoria, Durango, 1988, p. 46.

32 Liga de Agrónomos Socialistas, op. cit., p. 130.

33 Ibid., pp. 130-131.

34 Ibid., p. 132.

35 León, Arturo, op. cit., pp. 45-46. 
rurales. Durango fue de mucho interés: el profesor Guadalupe Rodríguez, iniciaba el establecimiento de relaciones y de organización en el medio rural, combatía el movimiento cristero y participaba en la conformación de grupos armados para luchar contra la sublevación militar "escobarista". ${ }^{36}$ En abril de 1929 fue aprehendido y liberado al final del mismo mes. Más tarde, era nuevamente detenido junto con otros compañeros. Acusado de sedición y de robo de armas, fue fusilado en mayo de ese año. ${ }^{37}$

Poco tiempo después, el gobierno mexicano declaraba terminada la reforma agraria e iniciaba el desarme campesino en los estados. Por otra parte, continuaban vigentes las estructuras latifundistas, las grandes haciendas apenas habían sido tocadas en pequeñas extensiones de tierras inútiles y las formas de financiamiento en el campo habían adquirido vicios, pues operaban "con propietarios particulares, no ejidatarios, con recomendados y políticos, mediante garantías insuficientes o de plano sin garantías". ${ }^{38}$ La mayor parte de los gobiernos utilizaba un discurso electoral y de manipulación frente a los peones; en cambio, las agrupaciones locales hacían esfuerzos para modificar las estructuras agrarias y terminar con la marginación y la miseria. No cabe duda que en la zona de Los Llanos -sobre todo en la región lagunera-, se conseguían transformaciones decisivas.

\section{Estado y agrarismo}

Al concluir el gobierno de Plutarco Elías Calles, la organización campesina mostraba un panorama de debilidad en su conjunto. Durante casi una década, las agrupaciones regionales, y luego las nacionales, habían realizado una labor sindical y política entre las masas rurales. Sin embargo, aunque se lograban algunos avances y reivindicaciones agrarias, en las zonas más productivas las principales fincas continuaban en poder de antiguas familias poderosas. Entre los casos más destacados se encontraban latifundios en la región algodonera de La Laguna, en Yucatán, Michoacán, Puebla, Veracruz, etcétera.

36 Agn, Presidentes, Emilio Portes Gil, exp. 4-565.

37 El Machete, 18 de mayo de 1929.

38 Laborde, Hernán, op. cit., p. 76. 
Los gobernantes habían vivido años de inestabilidad debido a las escisiones y enfrentamientos por el control del poder, lo cual ocasionaba que diversos sectores influyentes realizaran acuerdos y alianzas con asociaciones campesinas. Un caso lo representaba el Partido Nacional Agrarista (PNA) que era aliado de Obregón, pero más tarde decidiría apoyar la campaña de Calles. La mejor época del partido había sido durante el gobierno del primero. El abogado Antonio Díaz Soto y Gama -antiguo magonista y zapatista- y otros dirigentes del partido, impulsaban agrupaciones para acelerar la política de reforma agraria. En Morelos, Puebla, Tlaxcala y San Luis Potosí el PNA obtenía influencia; asimismo, mantenía la idea de efectuar convenciones regionales que expusieran la situación y las demandas rurales.

En el parlamento, en la prensa, así como en otros espacios, el PNA mostraba una crítica permanente a la política de Calles. Había decidido apoyar la reelección de Obregón y -más tarde- acusaba a los líderes laboristas de ser los responsables intelectuales de su asesinato. Con Calles las relaciones de los dirigentes del PNA eran difíciles. Cuando Calles convocaba a la formación del Partido Nacional Revolucionario (PNR), Soto y Gama se oponía a que los agraristas formaran parte de la nueva agrupación. Poco después, Calles -que se había convertido en un enemigo acérrimo de Soto y Gama-, fomentaba la división del PNA, objetivo que alcanzaría pronto. ${ }^{39}$

La Liga Nacional Campesina (LNC) se constituía a mediados de los años veinte, extendiéndose rápidamente su influencia por el país. La LNC representaba uno de los antecedentes más relevantes de las asociaciones agrarias que se constituirían en la cuarta década. Se creó con la participación de corrientes campesinas locales en la que actuaban líderes y figuras políticas de los estados; organizaba campañas para realizar la reforma agraria; impulsaba la dotación de armas a los peones para defenderse de la represión militar y de las guardias blancas rurales. Algunos de sus líderes poseían nexos con los gobiernos estatal y federal, otros con el PCM, y otros más intentaron mantener su independencia ante los partidos políticos. ${ }^{40}$

Los dirigentes de la LNC vivían en la inseguridad debido a la intensa persecución de la mayoría de los gobiernos. Muchos líderes actuaban en

39 Rivera Castro, José, "El PRM: de la movilización social al corporativismo autoritario", p. 61. 40 Véase el periódico El Machete, 1929-1931. 
medio de la clandestinidad, hecho manifestado hasta bien entrados los años treinta.

La LNC conocía divisiones, una de las más fuertes fue cuando estalló la rebelión "escobarista". Un grupo importante se organizaba para combatir la insurrección formando guerrillas en Veracruz, Coahuila y Durango. Dirigentes de la LNC decidieron participar en el proceso electoral para la presidencia del país. Con tal propósito, se constituyó el Bloque Obrero y Campesino, organismo que tenía un carácter electoral y transitorio. ${ }^{41}$

Esta última experiencia mostraba que la LNC había perdido mucha influencia, pues emergían escisiones que dispersaban a sus agremiados. A pesar de todos los problemas, grupos y ligas locales se movilizaban contra los enemigos de la reforma agraria. En la LNC se había generado una ruptura (abril de 1929) que originó el surgimiento de varias asociaciones, la primera, que estaba muy relacionada con el "tejedismo" veracruzano, se nombró LNC "Úrsulo Galván”. En esa entidad mantenía una dura contienda contra los sectores latifundista, ejército y caciquismo. La otra corriente estaba influida por altos personajes políticos como Lázaro Cárdenas, Emilio Portes Gil, Saturnino Cedillo y otros. Sus líderes eran Graciano Sánchez y Enrique Flores Magón. Esta segunda liga aglutinaba rápidamente a sectores y asociaciones agrarias regionales. Participaba en numerosos conflictos contra el poder de los hacendados y del caciquismo.

En marzo de 1933 el líder agrario chihuahuense Rodolfo Fuentes, Enrique Flores Magón y otros dirigentes constituían la Confederación Campesina Mexicana (CCM). Cárdenas, Cedillo y Portes Gil eran los principales políticos que la apoyaban. La nueva agrupación establecía comités agrarios para respaldar y defender a los trabajadores; en la mayoría de los estados, los gobernadores desconocían la representatividad de estas instancias e imponían a aliados incondicionales del poder local. Los principales dirigentes de la CCM se integraron al PNR, apoyaron la candidatura presidencial de Lázaro Cárdenas y llevaron a cabo un papel decisivo en la política de reforma agraria.

41 Idem. 


\section{Consideraciones finales}

Este trabajo ha tratado resaltar la situación social, la organización y luchas campesinas pertenecientes a varias entidades y zonas de México. El proceso armado de 1910 originó un ciclo de movilizaciones en el que muchos peones, y otros trabajadores del campo, participaron con armas en mano frente a las estructuras de poder dominantes. Como consecuencia de la Revolución, surgío una nueva legislación que sentaba las bases para la distribución y reintegración de tierras a los campesinos, créditos bancarios, educación, asistencia técnica y provisión de maquinaria agrícola a los labriegos. Los nuevos gobernantes hacían muchas promesas pero efectuaban pocos cambios; en suma, continuaba el viejo sistema latifundista con una parálisis estatal que impedía solucionar la problemática agraria.

Frente a esa realidad, grupos de campesinos habían luchado por transformar las estructuras imperantes. Como se mencionó anteriormente, las asociaciones agrarias hicieron un gran esfuerzo hasta conquistar -a mediados de los años treinta- medidas favorables a sus necesidades. En su campaña electoral, Cárdenas se comprometió a resolver las demandas campesinas; ya siendo presidente de México consideró necesario publicar un decreto oficial que reunificara a los trabajadores; con ese objetivo, el ex presidente Emilio Portes Gil recorrió el país, reunió a los diversos grupos de trabajadores y fue un actor determinante para que se constituyera la Confederación Nacional Campesina (CNC) que se convirtió durante varias décadas en la agrupación más significativa; ${ }^{42}$ junto con el Partido de la Revolución Mexicana (PRM) y la Confederación de Trabajadores de México (СтM), ayudarían a consolidar los cambios realizados en el medio rural, en la industria petrolera y otras reformas efectuadas por el régimen. El campesinado perdía su autonomía frente al proceso de incorporación de masas del gobierno cardenista.

42 González Navarro, Moisés, La CNC. 


\section{Bibliografía}

Almanza, Manuel, "Historia del agrarismo del estado de Veracruz", obra inédita, 4 tomos.

Azkinazy, Siegfred, El problema agrario de Yucatán, México, Botas, 1936.

Bartra, Armando, Los herederos de Zapata, México, ERA, 1985.

Domínguez, Olivia, Política y movimientos sociales en el tejedismo, Veracruz, Universidad Veracruzana, 1986.

Escárcega, Everardo, Historia de la cuestión agraria. El cardenismo, México, Siglo Xxi, vol. 5, 1990.

Falcón, Romana, El agrarismo en Veracruæ, México, El Colegio de México, 1977.

Gómez, Marte R., La reforma agraria de México. Su crisis durante el periodo 1928 1934, México, Porrúa, 1973.

González Navarro, Moisés, La CNC, México, unAm, 1977.

Joseph, Gilbert, Revolución desde afuera, México, Fondo de Cultura Económica, 1992.

Laborde, Hernán, "Cárdenas, reformador agrario", en PAIM, México, núm. 1, vol. IV, enero-marzo de 1952.

León, Arturo, El movimiento en los Llanos de Victoria, Durango, México, UAmXochimilco, 1988.

Liga de Agrónomos Socialistas, El colectivismo agrario en México. La Comarca Lagunera, México, s/e, 1940.

Maldonado, Alejo, Agraristas y poderpolitico, 1917-1938, Morelia, Universidad Michoacana de San Nicolás Hidalgo, 1993.

Marion, Odile, El agrarismo en Chiapas, 1524-1940, México, INAH, 1988.

Restrepo, Iván y Salomón Eckstein, La agricultura colectiva en México: La experiencia de La Laguna, $1^{a}$ México, Siglo Xxi, 1975.

Rivera Castro, José, "Política agraria, organizaciones, luchas y resistencias campesinas entre 1920 y 1928", en varios autores, Historia de la cuestión agraria mexicana. México, Siglo xxI, vol. 4, 1988.

SAF, Informe general de la Comisión de Estudios de la Comarca Lagunera, México, Cultura, 1930.

SAF, Regiones económico-agrícolas de la República Mexicana, México, Cultura, 1936. 
Salamini, H. F., Movilización campesina en Veracruz (1920-1938), México, Siglo XXI, 1979.

Santos Valdés, José, Matamoros. Ciudad Lagunera, México, Editorial y Distribuidora Nacional, 1973.

Silva Herzog, Jesús, El agrarismo mexicano y la reforma agraria, México, Fondo de Cultura Económica, 1980.

Tannembaum, Frank, "La revolución agraria mexicana", en PAIM, núm. 2, vol. IV, 1952.

Tobler, Hans Werner, La Revolución mexicana, México, Alianza Editorial, 1994.

vVAA, Agraristas y agrarismo. México, Consejo Técnico y Consultivo de la Liga de Comunidades Agrarias, 1992.

Weyl, Nathaniel y Silvia Weyl, "La reconquista de México", en PAIM, núm. 4, vol. vII, 1955. 